\title{
Knowledge, attitudes and practices related to HIV/AIDS among learners in Vhembe district of Limpopo Province
}

\author{
M Davhana-Maselesele, D(Phil) \\ Senior Lecturer, School of Health Sciences, University of Venda
}

LL Lalendle, PhD

Senior Lecturer, School of Humanities, University of Venda

Ushotanefe Useh, PhD

Senior Lecturer, Physiotherapy Department, University of Limpopo, MEDINSA Campus, Pretoria

Keywords: Knowledge; Attitudes; Behavioural practices; HIV, AIDS; Teenagers.

\section{Correspondence address:}

Dr M Davhana-Maselesele

School of Health Sciences

University of Venda

Private Bag X5050

Thohoyandou, 0950

Tel : (015) 962-8125

Fax : (015) 962-4749

E-mail:

mashudu.maselesele@.univen.ac.za

\section{Abstract: Curationis 30(3): $x-y$}

The purpose of this study is to investigate the knowledge, attitudes and practices related to HIV and AIDS among teenagers in rural schools in Vhembe district. This study focused on teenagers' sources of knowledge about HIV/AIDS; their knowledge of how to avoid contracting HIV/AIDS; their knowledge of the methods of transmission of the disease; their knowledge of condoms and usage levels; and people with whom they are comfortable to talk about HIV/AIDS.

This was a quantitative descriptive research design where a random sample of 128 participants between the ages of 14 and 19 years was selected. The participants were in grades 8 to 12 . The study recommended that holistic HIV/AIDS preventive programmes which were culture and gender sensitive be developed. Custodians of culture should be involved in dealing with HIV/AIDS. Parents should also play their role in discussing HIV/AIDS with their children in a non-threatening environment.

\section{Introduction}

HIV/AIDS is one of the fastest-spreading epidemics in the world. There are 42 million people living with HIV worldwide, and more than half of them are adolescents (UNAIDS, 2003). HIV/AIDS is a threat to all age groups, especially those that society relies on for economic prosperity. Research conducted in South Africa (Pettifor, Rees, Steffenson, Hlongwa-Madikizela, MacPhail, Vermaak \& Kleinschmidt, 2004:10) indicates that the prevalence rate of HIV was $10.2 \%$ among the 15-24 year-olds. This makes HIV and AIDS not only a health issue but a developmental problem as well, since the majority of the sufferers cannot fully contribute to society, as they tend to suffer from opportunistic infections and are mostly unwell.
AIDS is therefore a major health crisis, a threat to economic development and social solidarity (Nattrass, 2004:13). Dewaal (2003:11) argues that the impact of AIDS on economic development amounts to a development process run in reverse. In South Africa about 5.3 million people are living with HIV (HJORT, 2006:1). The burden of HIV and AIDS is not equally shared among the population as it affects the poorest more than other sectors of the population.

Information about HIV/AIDS is available in the world but such knowledge does not guarantee change in behaviour. De Gaston, Jensen, Weed and Tanas (1994:267) argue that there is a weak association between sexual knowledge, attitude and behavioural change. 
Understanding sexual culture is important in understanding the AIDS pandemic (Crothers, 2001; Nattrass, 2004:27).

There is a need to revisit the available preventive strategies such as HIV and AIDS education programmes, condom distribution, as well as the introduction of life-skills programmes in schools to track their impact on curbing the spread of the pandemic. According to UNICEF (2004:2), HIV/AIDS education programmes did not succeed in changing behaviour as there was over-emphasis on providing information on the pandemic without focusing on attitudes, values and skills related to human sexuality, social norms and gender issues. Furthermore, HIV and AIDS-specific services were not comprehensive. There was a lack of psycho-social skills, and teachers were not adequately trained and supported (UNICEF, 2004:2).

The high teenage-pregnancy rate is attributed to the inaccessibility of free confidential family planning, and poor communication with parents regarding safe sexual practices (Hopkins, 2000:16). The lack of youth friendliness services also contributes to the inaccessibility of services to teenagers (Adamchak, 2005:17).

Knowledge, attitudes and behavioural practices among school-going teenagers are important areas of research in a bid to understand what can be done to arrest the spread of the HIV and AIDS epidemic. Statistics show that young people (1024 years of age) account for more than $50 \%$ of all HIV infections worldwide (UNICEF, 2004:1).

Although teenagers appear to be the group most ignorant about sex, they are reported to be more likely to be exposed to the risk of HIV infection through their risky sexual behaviour and irresponsible conduct. This state of affairs is articulated by Fraser (2004:2), who argues that our world has been subjected to the tragedy of being in a "permissive society imposed upon us by the global secular trends", which has exposed our children to the dangers of contracting HIV and AIDS, where social norms and values are rapidly being eroded.

Teenagers are at a high risk of contracting HIV/AIDS as they are still at an exploratory stage regarding sexuality.
Allard-Hendren (2002:158) argues that teenagers are becoming sexually active at an earlier age and without using any contraception; may be victims of unplanned pregnancies. Involuntary sexual activities among girls who are younger than 14 years are at $74 \%$ (Kalmus, Davidson, Cohall, Laragus \& Cassel, 2003:87). Adams and East (2002:202) indicate that girls find it difficult or impossible to negotiate for safe sex because many of them are coerced into their first sexual experience, mostly by older men who usually have multiple sexual partners. This situation of unequal power relations further compromises the decision-making processes as these older and more experienced men are also in charge of making decisions on condom use, while their [women partners] are passive (Kalmus et al., 2003:87). This exposes them to other sexuallytransmitted infections as well as HIV and AIDS.

Dickson, Tetteth and Foy (2000:2) are of the opinion that teenagers usually engage in short-term sexual relationships that may lead them into having four or more successive sexual partners. This is irresponsible sexual behaviour that predisposes them to HIV infection. A study conducted in the Bushbuckridge area of Limpopo Province on perceptions of teenagers regarding teenage pregnancy revealed that poor sex education, peer influence and lack of access to health-care services were associated with high teenage-pregnancy rates (Richter \& Mlambo, 2005:65-67).

In a study of knowledge of and attitudes towards AIDS among female college students in Nagasaki in Japan, Maswanya, Moji, Aoyagi, Yahata, Kusano, Nagata, Izumi and Takemoto (2000:2), found that there was a discrepancy with regard to AIDS prevention among college students as well as the development of desirable attitudes towards people with HIV and AIDS. Mass media was viewed as the main source of information; acceptance of someone with HIV and AIDS was associated with knowledge of the pandemic. They suggested that education programmes in colleges should aim at reducing the discrepancy between general knowledge and desirable attitudes regarding HIV and AIDS. Maswanya et al. (2000:2) argue that the media tend to overemphasize the dreadfulness of HIV infection and this may produce irrational attitudes towards those with HIV and AIDS, especially in cultural context, and ignorance may lead to unnecessary fear and uncertainty among teenagers.

Studies by De Gaston, Jensen, Weed and Tanas (1994:267) and UNICEF (2004:2) have shown that there is no correlation between the amount of knowledge and change in behavioural patterns. This means that even when people have knowledge regarding HIV and AIDS it does not necessarily mean that there will be behavioural change.

Robinson, Dortzbach, Kiiti, Amalemba, Rakama, Hayman and Wamae (1996:335) indicate the importance of involving other stakeholders such as church leaders in enhancing behavioural change in preventing HIV, and also advocate the importance of caring for those affected by the pandemic in their communities and churches. This study proposes the drawing up of policies, plans and activities that will be used to control the upsurge of the disease. The churches were seen as critical and natural first lines of defence. This study also suggested the importance of considering the design, implementation, management and evaluation of effective, culturallyappropriate and locally sustainable HIV and AIDS programmes. It found that culture is the foundation upon which behaviour is built. Core values are important in behavioural change.

\section{Problem Statement}

The increasing number of infections raises a serious concern regarding the current preventive measures in place. About half of the people living with AIDS in Southern Africa live in South Africa where the death rate has increased dramatically in the age group of 15-39 (Nattras, 2004:24).

In South Africa more than $30 \%$ of 19 -yearold girls have given birth at least once (De Wet, Kaufman \& Staundler, 2000:1). In the Vhembe district, our area of focus for this study, statistics indicate that the district had 2072 births from teenagers below the age of eighteen within six months in 2003 (Health Statistics, 2003). The number of teenagers who requested termination of pregnancy was 386 during 2003 in the Vhembe District (Department of Health Statistics, 2003). Based on these statistics we can deduce that these teenagers were not practicing safe sex. 


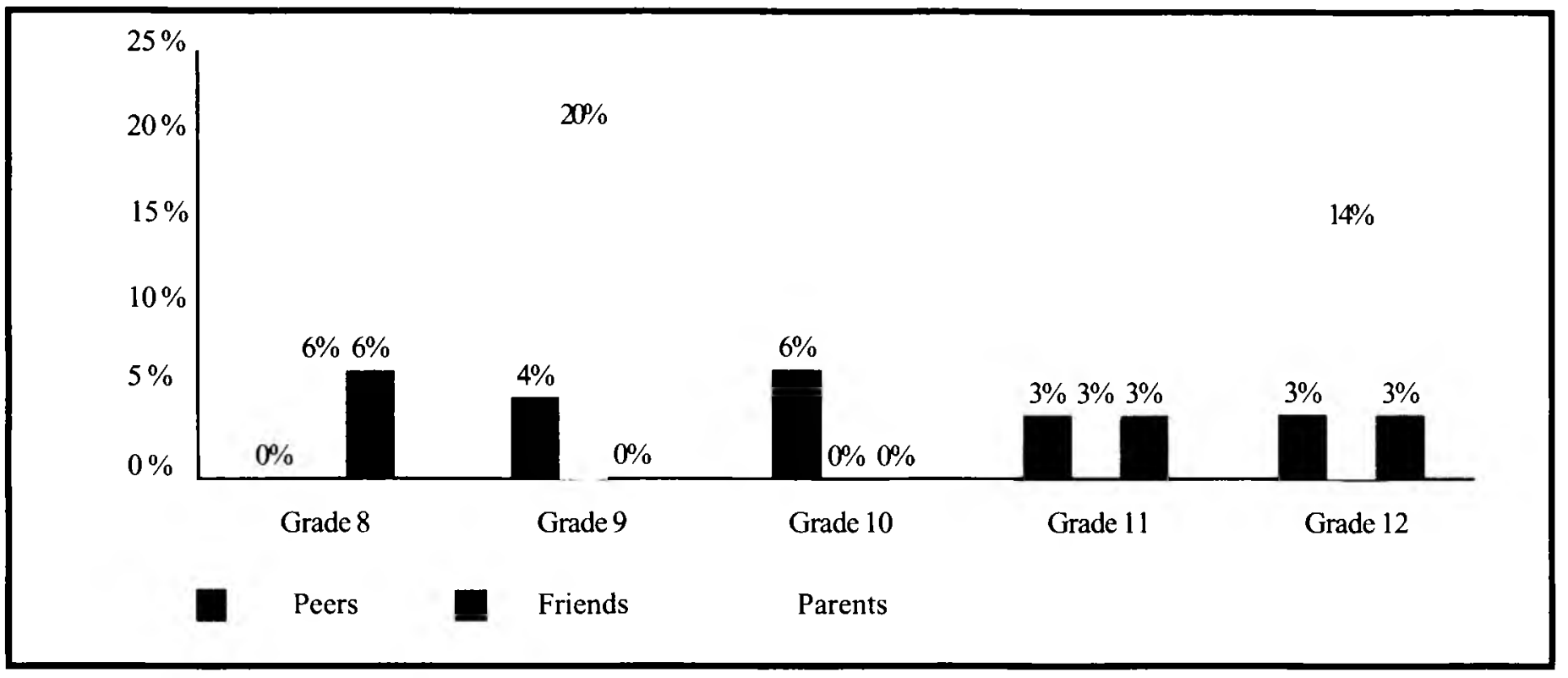

These numbers indicate teenagers' risk of exposure to HIV and AIDS.

Despite the preventive strategies, HIV and AIDS statistics appear to be increasing and the death toll among economically productive people is increasing. There is a need to step up the intervention to slow down the spread of $\mathrm{HIV}$ and AIDS. It is therefore important that knowledge regarding HIV and AIDS among teenagers be explored, and their attitudes as well as their behavioural practices be identificd in order to develop preventive programmes that will enhance behavioural change so as to eradicate the disease.

\section{Purpose}

The overall aim of the study is to assess the level of knowledge, attitudes and behavioural practices related to HIV prevention among learners in one of the rural schools in Vhembe district.

\section{Design}

A quantitative, descriptive research design was used to investigate the knowledge, attitudes and behavioural practices related to HIV and AIDS among learners in one of the rural schools in Vhembe district. Data was collected through the use of structured questionnaires.

\section{Population and Sampling}

In this study the research population comprised learners between the ages of 14 and 19 years. The study was conducted with 128 respondents who came from a rural school in one of the poorest villages in Vhembe district. Of the 128 respondents 67 were male and 61 were female. The respondents were systematically selected from each class in each grade, namely grades $8,9,10,11$ and 12 .

\section{Validity and reliability}

The questionnaire was developed in consultation with a statistician, and then a language specialist was consulted to assist with the translation of the questionnaire into Tshivenda (a local language). The questionnaires were pretested to check for clarity of items, time spent completing each questionnaire and consistency of responses. The questionnaires were given to 10 learners who were not included in the study. They all completed the questionnaire within 2030 minutes and they understood the questions.

\section{Data collection}

Structured questionnaires consisting of closed-ended questions were used to collect data. The questionnaire was divided into the following sections:

The first section included information on age, sex and grade. The second part assessed the level of knowledge regarding HIV and AIDS which included methods of transmission, prevention, how they got the information, and if they were to choose, whom they would prefer to teach them about HIV and AIDS. The questions generally entailed basic knowledge of HIV and whether they knew what a condom was and whether they had used one before. The questions were developed in English and translated into Tshivenda.

The researcher and an assistant visited the school and distributed the questionnaires to every third learner's desk. It took learners 20-30 minutes to complete the questionnaire.

\section{Data Analysis}

Statistical Package for Social Sciences (SPSS) version 14 was used to analyse data. Descriptive statistics of percentages and graphs were used to describe sources of information on HIV and AIDS, preferred sources of information, knowledge regarding prevention of HIV and AIDS as well as their behavioural practices.

\section{Ethical considerations}

Ethical measures were adhered to as permission for the research was sought from traditional leaders and the principal of the school. Most respondents were underage and therefore permission was sought from their parents/guardians. The principal of the school arranged for a meeting with the traditional leader who allowed the researchers to visit the village during their usual meetings at the kraal to explain the intended study to the parents. After a detailed explanation parents gave permission for their children to be involved in the study. Learners were requested to give permission and they were also informed that they could withdraw at any time if they did not feel like completing the questionnaires. Anonymity was ensured as they were not expected to write their names on the 


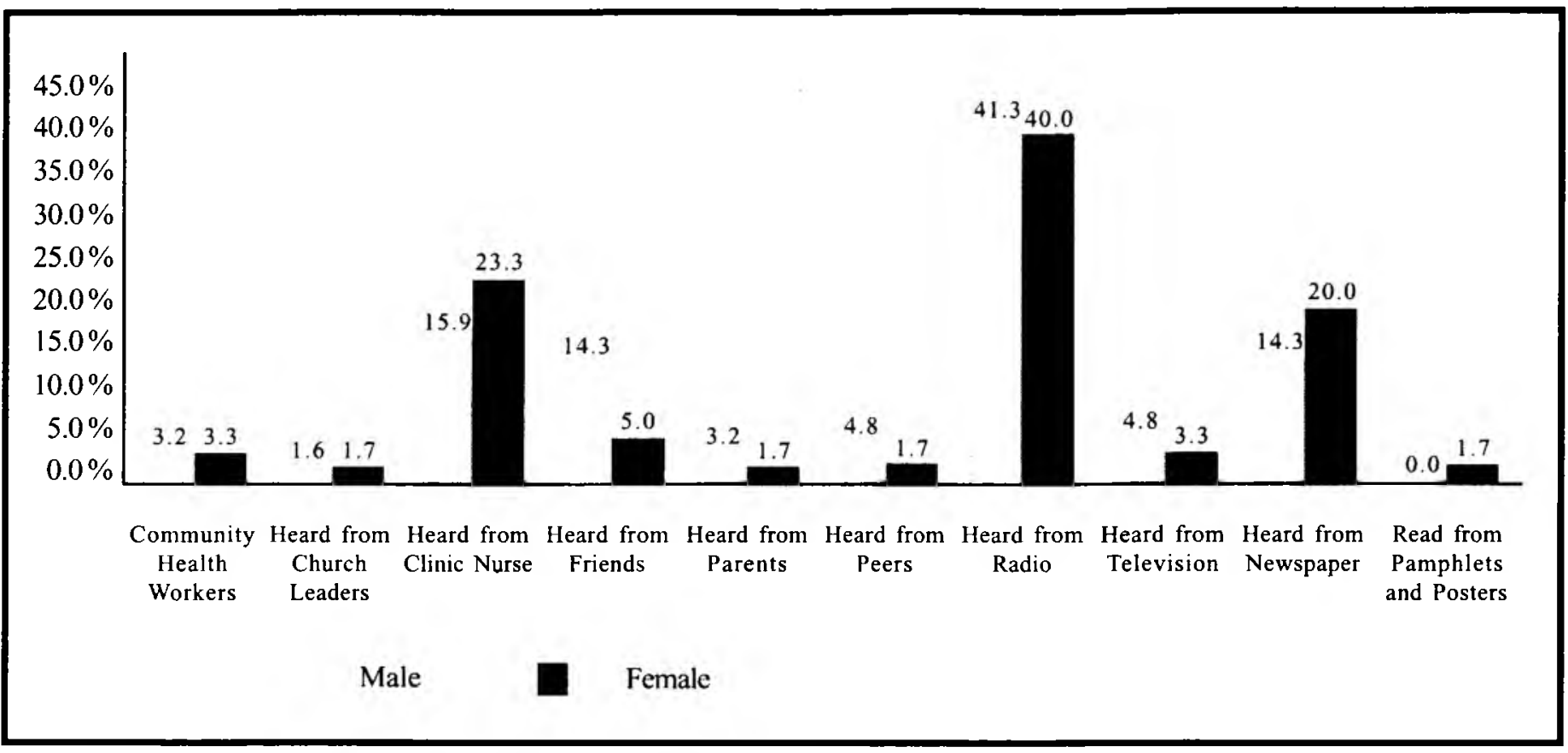

questionnaires.

\section{Results and discussion of findings}

The results are presented under the following subheadings: sources of information, knowledge of methods of HIV transmission, knowledge of the $\mathrm{ABC}$ of preventing transmission of HIV, and the use of condoms.

\section{Sources of information}

Graph 1 presents data collected from grade 8 to 12 learners on their sources of information about HIV and AIDS. From the data collected three sources were identified, namely peers, friends and parents.

It was noted that knowledge of HIV and AIDS was gathered mostly from friends, followed by peers and parents. Pupils in grades 9 and 12 got most of their information about HIV and AIDS from friends. Among the grade 8, 9 and 10 pupils, their parents did not feature among the people who talked to them or informed them about the epidemic. It was found that about $3 \%$ of the parents provided information on HIV and AIDS to their children in grades 11 and 12 .

Educating children at this level is considered very late since most of the children are already sexually active. Based on the data presented above, it is strongly recommended that parental guidance for children should start at an earlier age before they start their secondary education. At secondary education stage, it is a critical stage when they need to be informed more about the dangers of HIV and AIDS.

\section{Source of knowledge}

Information on source of knowledge is presented in figure 2.

On the sources of knowledge about HIV/ AIDS, figure 2 presents high school learners' perspectives based on gender (male and female). The most highly-rated source of information for both sexes $(41,3 \%$ male and $40 \%$ female $)$ is the radio. The outcome on source of knowledge is influenced by the availability of resources. For example, a television set is a luxury in this environment, while the radio is a common source of information.

It was interesting to note that males' other sources of information about HIV/AIDS were clinic nurses $(15,9 \%)$, followed by friends $(14,3 \%)$ and the newspaper $(14,3 \%)$, which rated higher than all other sources of knowledge. Females on the other hand relied on clinic nurses $(23,3 \%)$ and newspapers $(20 \%)$ and very few $(5 \%)$ indicated that they had heard about it from friends. Parents and church leaders were rated among the least-consulted sources of information. This is so because most parents and church leaders do not create an environment that allows for free discussion of sexual issues, including HIV and AIDS.

\section{Comfortable to talk to about HIV/ AIDS}

The collected data was analysed in such a manner that perspectives also took issues of gender into account. According to the data (figure 3), female teenagers felt comfortable talking about HIV and AIDS with their parents $(38.6 \%)$ and friends $(24,6 \%)$, followed by teachers $(14 \%)$ and nurses $(10.5 \%)$. We could ascribe the female level of comfort in talking to their parents to the fact that most of their families were composed of single parents who were likely to be mothers, while their male counterparts would prefer friends (35.5\%), followed by parents $(21 \%)$, then nurses $(19,4 \%)$ and teachers $(17,7 \%)$. It is interesting to note that both female and male pupils seemed to be less comfortable talking about this epidemic with peer educators and traditional healers, as these categories scored lower (both at 3,2\% - 3,5\%) than other categories. The ideas presented by the participants in this study about whom they trusted when it came to talking about this topic, suggested that boys still preferred an egalitarian environment when it came to comfort in talking about HIV/AIDS. Girls, on the other hand, still wanted to be connected to people whom they assumed to possess superior knowledge about the epidemic. Interestingly, both males $(21 \%)$ and females $(36 \%)$ felt comfortable talking about HIV/AIDS with their parents.

\section{Knowledge about HIV transmission methods}

Regarding knowledge about HIV transmission methods; sexual intercourse was indicated as the major mode of 


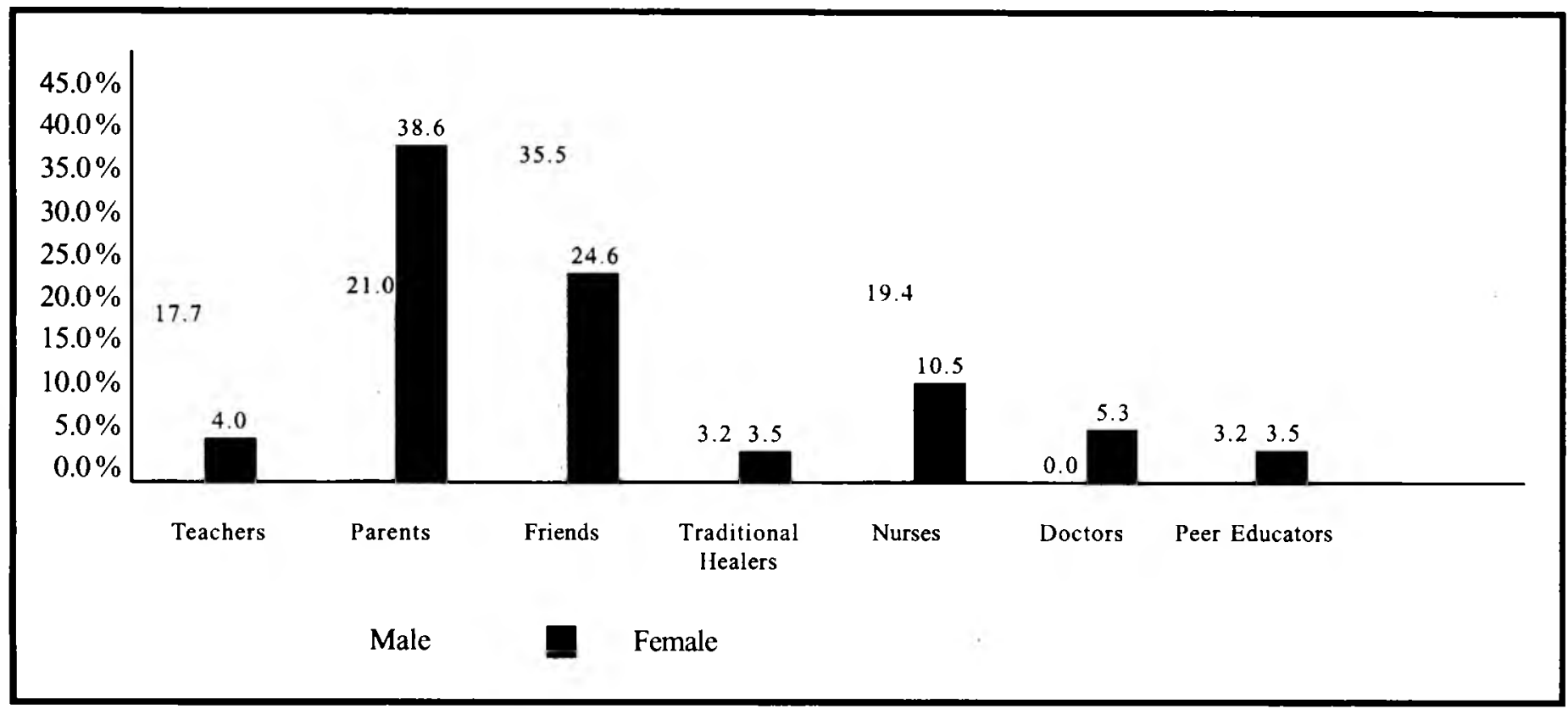

transmitting the pandemic for both males $(71,4 \%)$ and females $(75 \%)$ and blood transfusion (males, 39,7\% and females, $40 \%$ ). Sharing of needles and razors was cited as the second means (males 39,7\%; females $35 \%$ ) of HIV transmission after sexual intercourse by both girls and boys.

This group rated breast milk, pregnancy and delivery as the lowest on knowledge regarding methods of transmission of HIV.

This data presents a challenge to the present health system as it suggests that teenagers are less informed about pregnancy, childbirth and breast-feeding as common means of contracting or transmitting HIV and AIDS, even to unborn babies and infants.

There might be a need to acknowledge that if societies are not open about the divergent modes of transmission so as to offer holistic educational programmes to the teenagers, the scourge of HIV and AIDS will take a long time to be combated.

\section{Figure 4 Knowledge of methods of transmission}

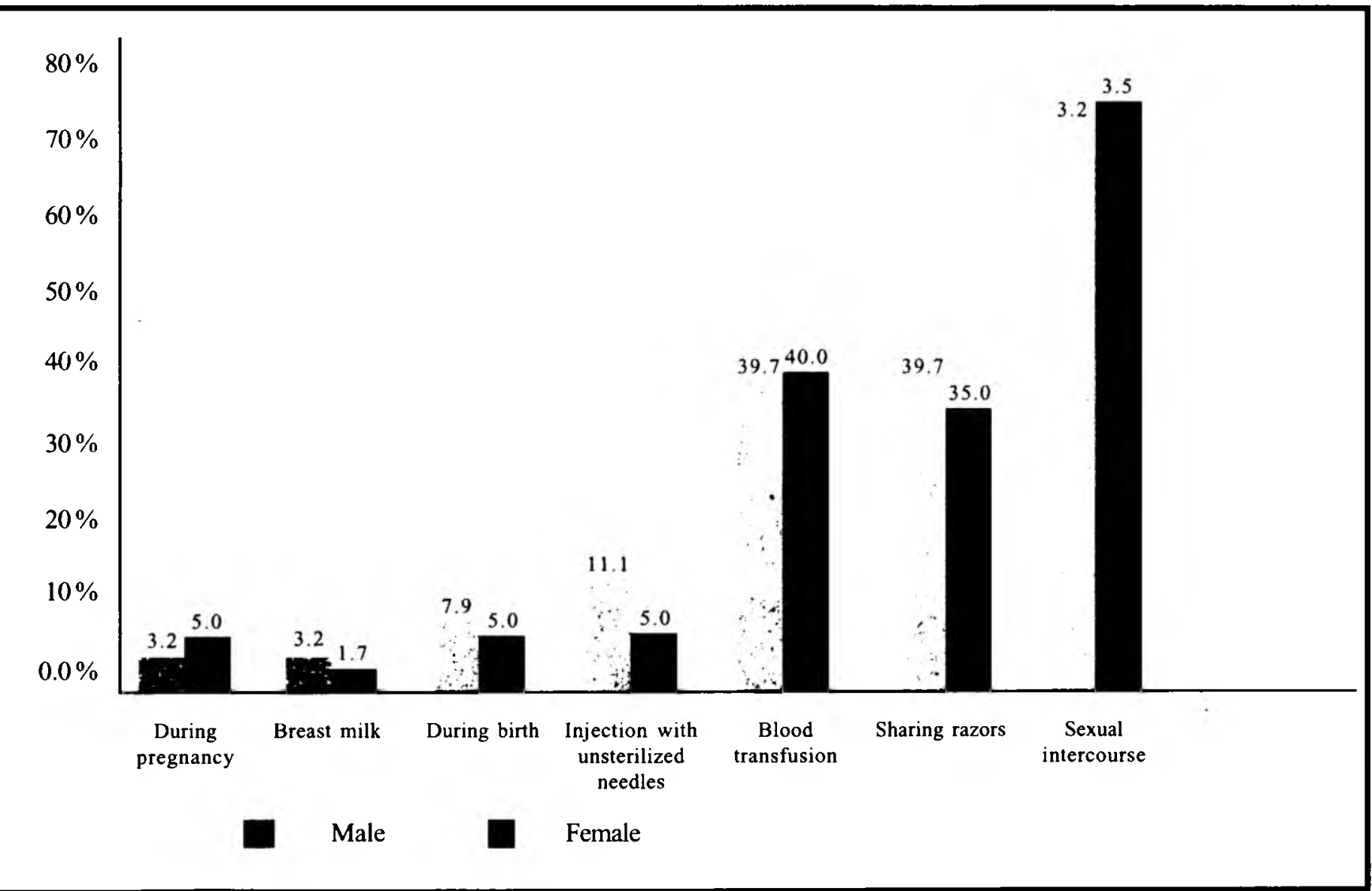




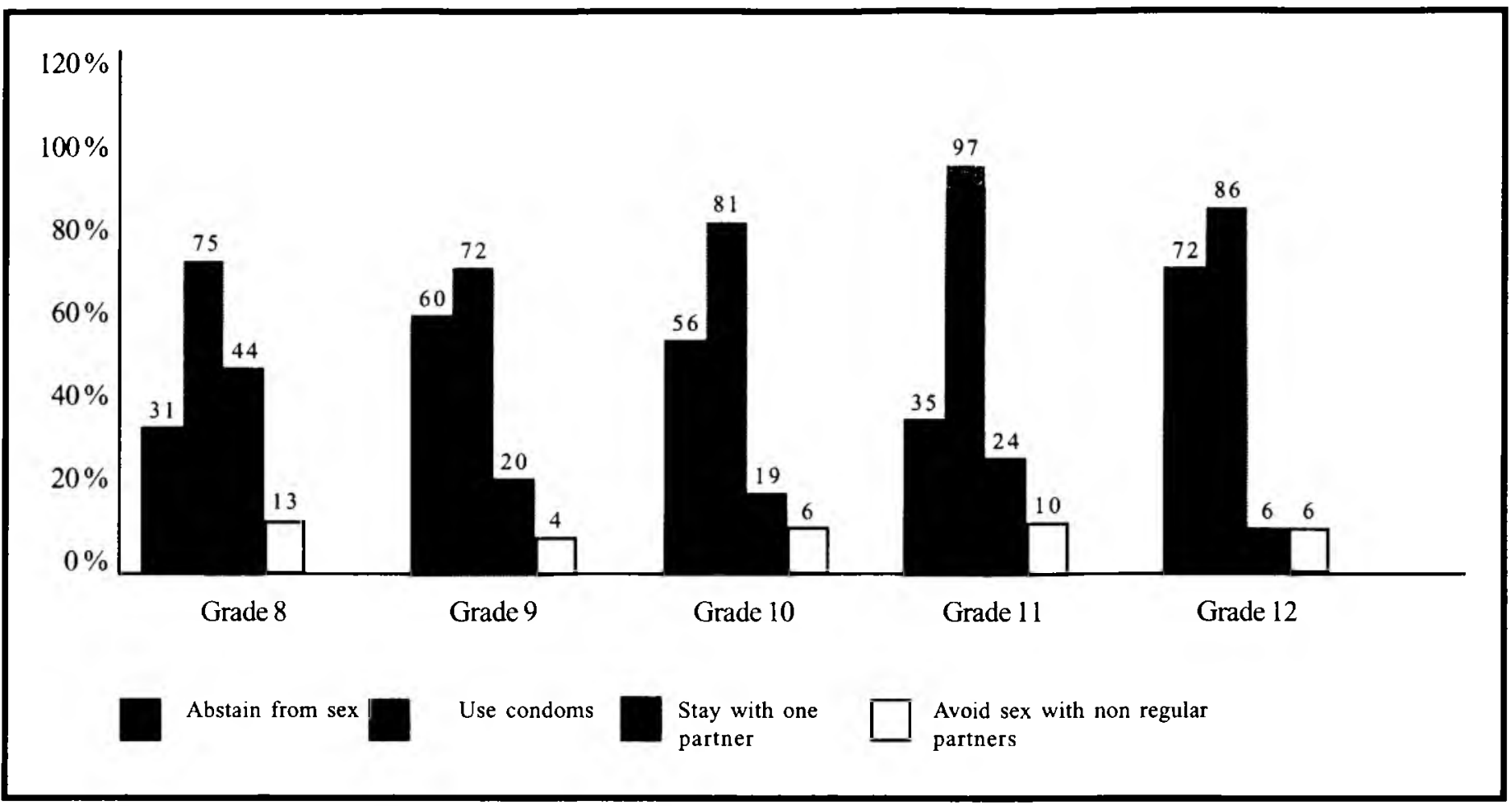

\section{Knowledge about the $A B C$ of preventing HIV transmission}

With regard to knowledge on prevention of the transmission of HIV and AIDS, the use of condoms rated high in all grades among the high school learners, whilst abstinence from sex rated second, and staying with one partner rated third. Avoidance of sex with non-regular partners rated the least in all grades. This data tends to suggest that as early as grade 8 , which is the cohort group of 14 - 15-year-olds, cited condom as the preferred way of preventing transmission of the virus. This goes against the common wish that children at these ages should regard abstinence as the most preferred mechanism against the spread of HIV and AIDS. Using a condom in this list should be portrayed as the last resort, if one fails to abstain or be faithful. (See figure 5)

\section{The use of condoms}

Knowledge about condoms and where to get them was well demonstrated by both males and females, as they all affirmed yes. They presented themselves as having a clear idea of what a condom is. They were also aware of where to get them. A difference in responses between genders was also observed (males $90.9 \%$ and females $86 \%$ ). The responses to these questions might be ascribed to the fact that girls could not request their sexual partners to use condoms, or if they requested them to do so, their partners

Figure 6 Knowledge about condoms

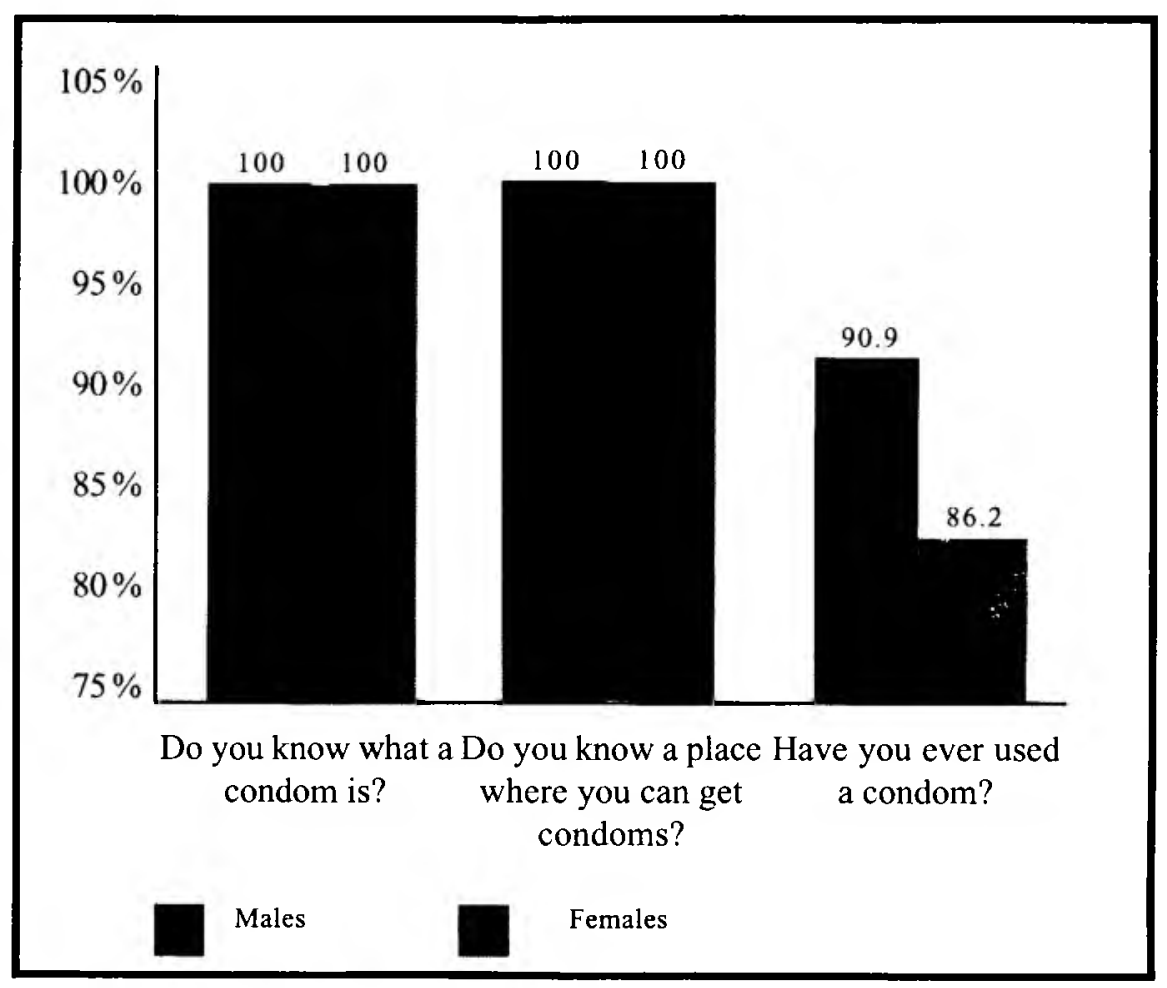

refused to use condoms. This revealed that females were not empowered regarding their sexual practices.

\section{Recommendations}

HIV and AIDS preventive programmes should be holistic and culture sensitive. Programmes should also target the available resources within the community. It is important to develop innovative strategies in the prevention of HIV/AIDS. Intervention programmes should be developed to enhance behavioural change that incorporates cultural practice.

Parents/guardians should take their roles as parents and should start to discuss sexuality issues with their children as they are most trusted by their own children. They should start sexuality education at an early stage in life before 
the child start secondary education. Findings revealed that both sexes felt comfortable talking about HIV/AIDS with their parents, so it is important for parents to create an atmosphere that will enhance discussion of HIV/AIDS and not wait until something goes wrong. They should educate their children in a nonthreatening environment; make their children feel comfortable to discuss sexuality issues with them without any fear. Parents are expected to inculcate moral values and beliefs through socialisation as well as role modeling.

More information about sexuality education and HIV/AIDS should be made available through the local radio station as this is the most accessible form of media in the village. Special programmes for the youth could be helpful in this regard. Teams of trained health educators should visit the village regularly to encourage discussion regarding reproductive health issues.

There is a need to develop youth-friendly, non-judgmental reproductive health services to encourage them to use the resources. If possible most of the people who render these services should be the youth or young adults so as to create an environment which allows for free discussion. Holistic information about HIV transmission should be provided. Discussion groups should be held to encourage openness about HIV/AIDS issues. Peer educators, if properly trained, could enhance behavioural change among teenagers.

Teachers should be trained in sexuality education and HIV/AIDS to stimulate their interest in teaching learners. Their teaching strategies should enhance a friendly classroom environment which is non-threatening and gender sensitive to encourage learners to speak freely about sexuality. Interactive approaches such as role plays, group discussions and brainstorming sessions will enhance free discussion of sexuality issues. This will improve the quality of their teaching.

Carter in Fraser (2004:2) argues that learned behaviour can be unlearned. If we are to succeed in doing that, we need to restore moral values. This should be a communal effort involving the custodians of culture. Traditional leaders and the elderly should be involved, for example, during the initiation of youths. Sexuality education and HIV/AIDS should be included in the training. The youth should be kept busy through the formation of entertainment groups such as traditional dances at the kraal. Songs that send messages about HIV should be formulated. This encourages the community to make use of its own resources. HIV preventive programmes should target the youth where they are found in large numbers such as at initiation schools, youth camps and conferences.

\section{Acknowledgement}

We would like to thank the National Research Foundation (NRF 10857) for funding this project.

\section{List of References}

ADAMCHAK, SE 2005: Lesson Learned from the Global Agenda of the Frontiers in Reproductive Health Program. Family Health International.

ADAMS, J \& EAST, P 2002: Sexual assertiveness and adolescent sexual rights. Perspective on Sexual and Reproductive Health. Academic Research Library, 34(4)36-50.

ALLARD-HENDREN, R 2002: Alcohol use and adolescent pregnancy. Available at: http:www.nursingcenter.com/ (Accessed 15 January 2006)

CROTHERS, C 2001: Social Factors and HIV/AIDS in South Africa: A Framework and Summary. Society in Transition 32(1) 5-21.

DE GASTON, JF; JENSEN, L; WEED, SE \& TANAS, R 1994: Teacher philosophy and program implementation and the impact of sex education outcomes. Journal of Research and Development in Education 27:265-270.

DEPARTMENT OF HEALTH. 2003: Statistics Limpopo Province.

DEPARTMENT OF HEALTH. 2000 2005: Strategic plan. South Africa.

DEWAAL, A 2003: HIV/AIDS and Emergencies: Challenges of Measurement and Modelling. Presentation for the United Nations Regional Inter-Agency Coordination and Support Office.

DE WET, T; KAUFMAN, C \& STAUNDLER, J. 2000: Adolescent Pregnancy and Parenthood in South
Africa.

DICKSON-TETTETH, K \& FOY, D 2000: The National Adolescent- Friendly Clinic Initiative: Handbook of adolescent sexual and reproductive health care. Academic Research Library, 23(2)2-22.

FRASER, H 2004: HIV/AIDS: Childhood Sex - Common sense \& evidence. Nation Newspaper Barbados

GRUNSIET, A \& KIPPAX, S 1997: Impact of HIV and sexual health education on the sexual behaviour of young people: a review update. UNAIDS.

HJORT, L 2006: Sexism, Youth and HIV in South Africahttp:// alternativesinternational.net/ateur57.html (Accessed 10 November 2006).

HOPKINS, A 2000: Teenage pregnancy. Adolescence: Change and change. Available at: http://www. inside.bord.edu/academic/specialprop/ darling/adsex.htm (Accessed 10 November 2006).

KALMUS,D; DAVIDSON,A; COHALL, A; LARAGUS, D \& CASSEL, C 2003: Preventing sexual risk behaviours and pregnancy among teenagers: Linking research and programs perspectives on sexual reproductive health. Academic Research Library, 35 (2) 734-771.

MASWANYA, E; MOJI, K; AOYAGI, K; YAHATA, Y; KUSANO,Y; NAGATA, K; IZUMI, T AND TAKEMOTO, T 2000: Knowledge and attitudes toward AIDS among female college students in Nagasaki, Japan Health Education Research, Vol. 15(1): 5-11.

MCCORMICK, S 2004: Sexually Transmitted Diseases. Adolescence: Change and change. Available at: http:// www. inside.bord.edu/academic/ specialprop/darling/adsex.htm

NATTRASS, N 2004: The Moral Economy of Aids in South Africa. Cambridge University Press.

PETTIFOR, AE; REES, HV; STEFFENSON, A; HLONGWAMADIKIZELA, L; MACPHAIL, C; VERMAAK, K \& KLEINSCHMIDT, I 2004: HIV and sexual behaviour among young South Africans; a national survey of 15-24 year-olds. Johannesburg: Reproductive Health Research Unit. 
University of Witwatersrand.

RICHTER, MS \& MLAMBO, GT 2005:

Perceptions of rural teenagers on teenage pregnancy. Health SA Gesondheid, $10(2) 61-69$.

ROBINSON, P.; DORTZBACH, D.; KITT.N.; AMALEMBA, W.; RAKAMA, B.; HAYMAN, J.; WAMAE, M1996: Working with the church in Kenya to prevent the spread of HIV/AIDS. HIV/ AIDS Prevention Collection 330-342.

UNICEF. 2004: Education and HIV/AIDS.

UNAIDS. 2003: UNAIDS (2003) AIDS epidemic update, December. Available from http://w.w.w.unaids.org/en/ default.asp. (Accessed 10 November 2006). 